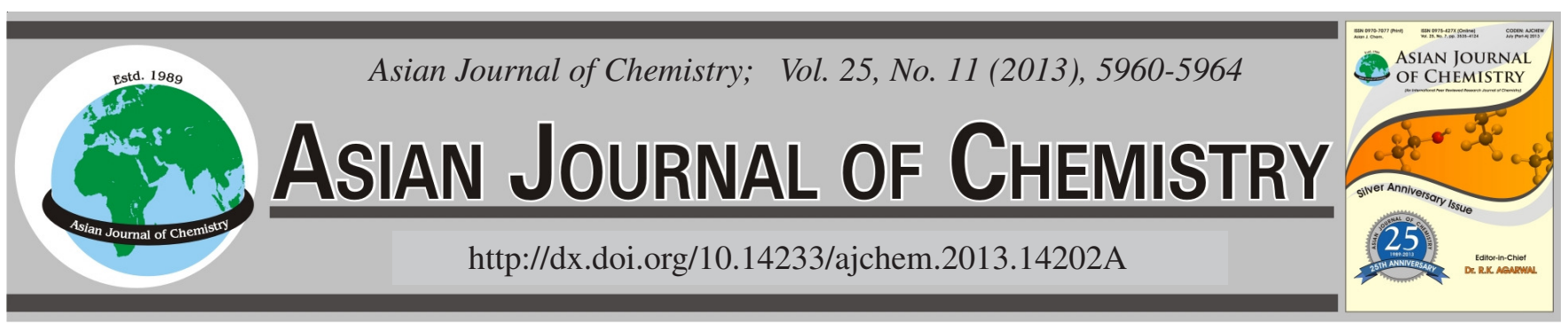

\title{
Effect of Conventional and Ultrasonic Assisted Bleaching on Colour Fastness Properties of Reactive Dyed Cotton Fabric
}

\author{
Assad Farooq ${ }^{1, *}$, Muhammad Azeem Ashraf $^{1}$ and Muhammad Mohsin ${ }^{2}$
}

${ }^{1}$ Department of Fibre \& Textile Technology, University of Agriculture, Faisalabad, Pakistan

${ }^{2}$ Department of Textile Engineering, University of Engineering \& Technology, Lahore (Faisalabad Campus), Pakistan

*Corresponding author: Fax: +92 41 9201267; Tel: +92 3006628872; E-mail: assadfarooq@googlemail.com

\begin{abstract}
The uniformity of dyed cotton materials largely depends upon the efficiency of fabric preparatory processes. For uniform colouration all natural and added impurities from cotton are removed by scouring and bleaching by treating with harsh chemicals at elevated temperatures which consumes much of energy. The effective use of ultrasound in textile wet processing provide benefits such as reduced energy costs and increased product quality in less time. In this research work cotton fabrics were dyed after bleaching by conventional and ultrasonic assisted bleaching technique. Colour fastness properties of reactive dyed cotton fabrics such as washing, rubbing, ironing and light were determined and compared to evaluate the effect of bleaching. The study showed that pre-treatments have a significant effect on fastness properties of fabrics. The fabric samples dyed after ultrasonic bleaching clearly showed better fastness properties even at low temperature and time as compared to conventional technique.
\end{abstract}

Key Words: Ultrasound, Bleaching, Colour fastness, Cavitations, Cotton, Pretreatment.

ᄂ - - - - - - - - - - - - - - - - - - - - - - - - - - -

\section{INTRODUCTION}

Despite the increasing production of synthetic fibres, cotton is still the king of all fibres due to its versatile properties. But unlike synthetic fibres, cotton must be prepared before colouration and any other finishing process. Raw cotton contains up to $96 \%$ cellulose and other non-cellulosic materials such as proteins, pectins, oils, waxes and mineral matters in small amounts ${ }^{1}$. Greige fabrics which entered into textile wet processing section contain all these natural as well as acquired impurities. For uniform colouration of textile materials all these impurities have to be removed completely. The uniformity of coloured materials largely depends upon the efficiency of preparatory processes especially for light and medium shades.

The bleaching process is used to give textile materials perfectly white and bright appearance. Major chemicals used as bleaching agents are hydrogen peroxide, sodium hypochlorite and sodium chlorite and sodium perborate ${ }^{2}$. Although conventional bleaching process gives permanent and high degree of whiteness but it has some drawbacks such as effluents and high energy consumption.

The ultrasonic waves have been used for cleaning of small electronic parts, cables, rods, wires and teeth etc. Sound waves having frequency from $20-500 \mathrm{kHz}$ are known as ultrasound. Unlike other waves, the direction of propagation of ultrasonic waves is only longitudinal. Compressions and rarefactions are produced during the propagation of ultrasonic waves which results in cavities. Cavitations are the principle phenomena behind most of the ultrasonic treatments in wet processing which causes the formation and collapse of small bubbles of $a^{3}{ }^{3}$. The formation and collapse of theses small bubbles results in the formation of micro jets of velocities 100-150 $\mathrm{m} / \mathrm{s}$ directed towards the surface of the materials. Theses micro jets increase flow of chemicals and mass transfer between yarns pores $^{4}$.

Ultrasonic energy intensifies the diffusion of chemicals and improves the washing treatments under the effects of cavitations even at low temperature and time which results in considerable saving of chemicals and energy ${ }^{5}$. The micro agitations by ultrasound enhance the removal of grease and stains in conventional laundering without effecting the surface and mechanical properties ${ }^{6}$. Further ultrasonic waves have been effectively used in the textile wet processing including scouring ${ }^{7}$, enzymatic bleaching ${ }^{8}$ and dyeing 9 . The influence of ultrasound waves on dyeing has mainly three effects which include dispersion of large dye molecules into small particles which results in uniform dispersions of dyes, removal of entrapped air and gas molecules from fibre capillaries and inter yarn spaces which increases dye fibre interactions and increasing the rate of diffusion of dyes into the fibres by breaking the outer hydrophobic layer covering the fibres ${ }^{10}$. 
The incorporation of ultrasonic energy in textile processing can provide considerable benefits such as energy saving, low processing time and improved product quality. However a thorough study of the relevant literature did not give any direct information about the effect of ultrasonic assisted bleaching on the colour fastness properties of dyed fabrics. Therefore in this research study, efforts have been made to evaluate and compare the dyeing performance (colour fastness properties) of cotton fabrics bleached with ultrasonic assisted and conventional process. This will help to find out the effect of ultrasonic bleaching on colour fastness properties.

\section{EXPERIMENTAL}

Industrially scoured $100 \%$ cotton woven fabric having construction 72 warp yarns and 72 weft yarns with yarn count $40 \mathrm{~s}$, Analytical grade reagents; hydrogen peroxide $\left(\mathrm{H}_{2} \mathrm{O}_{2}\right)$, sodium hypochlorite $(\mathrm{NaOCl})$, sodium perborate $\left(\mathrm{NaBO}_{3}\right)$, sodium hydroxide $(\mathrm{NaOH})$, Alkavan GAL (stabilizer), sandozine MRN (wetting agent), bactosol AP (antioxidant), sodium bisulphite $\left(\mathrm{NaHSO}_{3}\right)$, Red $\mathrm{C}_{4} \mathrm{BLN}$ (C.I. Reactive Red 195) obtained from Sandal Dyestuff Pakistan Ltd, sodium carbonate $\left(\mathrm{Na}_{2} \mathrm{CO}_{3}\right)$ and sodium sulphate $\left(\mathrm{Na}_{2} \mathrm{SO}_{4}\right)$.

ELMA TRANSSONIC T 460/H ultrasonic bath with 35 $\mathrm{KHz}$ frequency (Elma $\mathrm{GmbH} \& \mathrm{Co} \mathrm{KG}$ ), Lab scale exhaust HT dyeing machine (Advance System Logic), SDL Atlas Crock meter for rubbing fastness, Launder-o-meter (SDL Atlas, USA) for washing fastness tests and Atlas Ci3000 Weather-Ometer for light fastness testing.

Bleaching: Scoured cotton samples were bleached using the recipes mentioned below by conventional and ultrasonic assisted methods.

Recipe for hydrogen peroxide: $\mathrm{H}_{2} \mathrm{O}_{2}(50 \%): 10 \mathrm{~mL} / \mathrm{L}$, $\mathrm{NaOH}(50 \%): 6 \mathrm{~mL} / \mathrm{L}$, Stabilizer (Alkavan GAL): $1 \mathrm{~mL} / \mathrm{L}$, Wetting agent (Sandozine) MRN: $1 \mathrm{~mL} / \mathrm{L}$, liquor ratio: 20:1, pH: 10 .

Recipe for sodium hypochlorite: $\mathrm{NaOCl}(12 \%): 10 \mathrm{~mL} /$ L, Soda ash: $5 \mathrm{~g} / \mathrm{L}$, Wetting agent (Sandozine MRN): $1 \mathrm{~mL} / \mathrm{L}$, liquor ratio: 20:1, pH: 9 .

Recipe for sodium perborate: Sodium perborate: 10 $\mathrm{mL} / \mathrm{L}$, sodium silicate: $1 \mathrm{~g} / \mathrm{L}$, Wetting agent (Sandizine MRN): $1 \mathrm{~mL} / \mathrm{L}$, liquor ratio: 20:1.

Conventional bleaching method: The scoured samples were put into the bleaching baths prepared according to the recipes mentioned one by one. The bleaching was carried out for 30,45 and $60 \mathrm{~min}$ at 30,60 and $90{ }^{\circ} \mathrm{C}$, respectively. The stirring was continuously done by a glass rod to ensure the uniform bleaching. After the required time cooling was allowed and samples were taken out of the bleaching baths. The samples were washed twice in hot and cold water and dried.

Ultrasonic assisted bleaching method: The scoured samples were put into the bleaching baths prepared according to the recipes mentioned. Then, the bleaching baths were placed in ultrasonic instrument ELMA TRANSSONIC T 460/ $\mathrm{H}$. It has a $35 \mathrm{kHz}$ frequency and a stainless steel round bath to which one barium titanate piezoelectric spread-beam sandwich transducer was firmly fixed beneath the bottom. The bleaching was carried out for 30, 45 and $60 \mathrm{~min}$ at 30, 60 and
$90{ }^{\circ} \mathrm{C}$, respectively. After the required time the bleaching baths were removed from the ultrasonic instrument and allowed to cool. Then the samples were taken out, rinsed in hot and cold water, respectively and dried.

Treatments after bleaching: After bleaching some residuals of hydrogen peroxide and sodium hypochlorite remained on the fabrics. To avoid the damage of the fabric due to residual peroxide and chlorine following after treatments were carried out.

Anti-hydrogen process: Fabric samples bleached with hydrogen peroxide were put in the bath containing antioxidant (Bactosol AP) at $40^{\circ} \mathrm{C}$ and stirring was continuously done for $20 \mathrm{~min}$. Then samples of the fabrics were washed in cold water and dried.

Anti-chlorine process: To avoid the damage of the fabric due to residual chlorine, the fabric samples were treated with $1 \mathrm{~g} / \mathrm{L}$ sodium bisulphite for $15 \mathrm{~min}$ at $40^{\circ} \mathrm{C}$ using liquor ratio 20:1. Continuous stirring was done for better reaction. After 15 min fabric samples were taken out, washed in cold water and dried.

Dyeing of bleached samples: After conventional and ultrasonic bleaching all samples of the cotton fabric were dyed with reactive dye Red C4BLN (C.I. Reactive Red 195) using the recipe mentioned below. After dyeing all dyed samples were thoroughly soaped and rinsed with hot and then cold water to remove any unfixed dye from fabric.

Recipe: Reactive dye: $3 \%$ (o.w.f), sodium sulphate: 50 $\mathrm{g} / \mathrm{L}$, sodium carbonate: $20 \mathrm{~g} / \mathrm{L}$, time: $1 \mathrm{~h}$, temperature: $65^{\circ} \mathrm{C}$.

Evaluation of colour fastness properties: The dyed samples were then evaluated for the washing fastness, rubbing fastness, ironing fastness and light fastness according to the ISO standards.

Colour fastness to washing: This method was intended for accessing the resistance of colour of textiles to the action of soap solution used in mechanical washing. For ISO 105C03 washing test, specimens were put in Launder-o-meter containing the soap solution ( $5 \mathrm{~g} / \mathrm{L}$ soap and $2 \mathrm{~g} / \mathrm{L}$ soda ash) for $0.5 \mathrm{~h}$ at $60^{\circ} \mathrm{C}$, rinsed thoroughly, hydro extracted and then dried. The amount of colour change was determined by means of standard grey scale ${ }^{11}$.

Colour fastness to rubbing: Dyed samples were tested for rubbing fastness as directed in ISO $105 \mathrm{X} 12$. This test is designated for determining the degree of colour which may be transferred from the surface of the coloured textile materials to other surface by rubbing. Two tests were carried out, one for dry rubbing, the other for wet rubbing. In dry rubbing test, a piece of white cloth was rubbed against the dyed fabric for 10 complete turns using crock meter. The white sample was removed and the change of colour was noted by standard grey scale. While in wet rubbing, white test specimen was made wet by distilled water. After rubbing for 10 cycles, specimen was dried by air; the change of colour was assessed by grey scale for rubbing test ${ }^{12}$.

Colour fastness to ironing: This method was supposed to assessing the resistance of colour of textiles to ironing. The test was carried out for dry and wet fabrics. The standard procedures $^{13}$ of dry and wet ironing fastness were followed for testing the samples as mentioned in ISO 105-X11. 
Colour fastness to light: The colour fastness to light of the specimen was evaluated by comparison of the colour change of the exposed portion to the masked control portion of the test specimen or unexposed original material, using the blue scale, for colour change. The light source was xenon arc lamp containing a filter so that the ultraviolet spectrum is steadily reduced. Standard test procedures as mentioned in ISO 105-B02 were followed ${ }^{14}$.

Atmospheric conditions: The testing of samples was carried out in laboratories where standard atmospheric conditions $65 \pm 2 \%$ relative humidity and $20 \pm 2{ }^{\circ} \mathrm{C}$ were maintained.

\section{RESULTS AND DISCUSSION}

Colour fastness to washing: The results of washing fastness of conventionally reactive dyed cotton fabric samples after bleaching with conventional as well as ultrasonic assisted techniques are given in Table-1. These results show that most of the samples treated with conventional technique have washing fastness good to very good (3-4) but at the same conditions the dyed samples after ultrasonic assisted bleaching technique show better washing fastness. The washing fastness for most of the samples of ultrasonic assisted technique was very good (4).

In case of hydrogen peroxide, the grey scale rating of washing fastness for conventional technique was mostly good to very good (3-4) for all bleaching agents hydrogen peroxide, sodium hypochlorite and sodium perborate. The ultrasonic assisted technique gave mostly very good to excellent (4-5) rating of washing fastness for hydrogen peroxide and very good (4) rating for sodium hypochlorite and sodium perborate. Cotton fabrics dyed after ultrasonic assisted bleaching with hydrogen peroxide showed better washing fastness results than other agents. It could be due to increased production of hydroxyl ions ${ }^{15}$ which results in better preparation of fabrics and finally gives more even dyeing of fabrics.

In case of bleaching durations of 30 and 45 min the grey scale rating of washing fastness for conventional technique was mostly good to very good (3-4) while very good (4) for $1 \mathrm{~h}$. The ultrasonic assisted technique gave mostly very good (4) rating for washing fastness at all durations.

For temperature, the grey scale rating of washing fastness for conventional technique was mostly good to very good (3-4) at 30 and $60{ }^{\circ} \mathrm{C}$ and very good (4) for $90{ }^{\circ} \mathrm{C}$ while the ultrasonic assisted technique showed very good (4) rating of washing fastness at temperatures 30,60 and $90{ }^{\circ} \mathrm{C}$.

On the basis of overall results it is clear that ultrasonically bleached samples shows better results with respect to washing fastness. It is also clear from the Table- 1 that in case of ultrasonically bleached samples better results of washing fastness have been achieved at lower temperature and less time, as compared to the conventionally bleached samples.

Colour fastness to rubbing: The results obtained by grey scale for rubbing fastness (dry and wet) of dyed cotton fabrics after bleaching with conventional and ultrasonic techniques by selecting different bleaching agents, temperature and durations are presented in Table-2. The results were found to be better for some of the ultrasonically bleached samples as compared to the conventionally bleached samples. The rating for the dry and wet rubbing fastness was mostly good to very good (3-4) for conventional technique while the samples dyed after ultrasonic assisted bleaching showed mostly very good (4) rating.

Cavitations produced under the effect of ultrasonic waves increased the circulation of chemicals which results in increased removal of impurities. With the removal of impurities absorbency of textile fabrics is increased significantly ${ }^{7}$ which enhance the penetration of dye molecules inside the fibre structure. Better fixation of dyestuff in fabric results in improved rubbing fastness.

\begin{tabular}{|c|c|c|c|c|c|c|c|c|c|c|}
\hline \multicolumn{11}{|c|}{$\begin{array}{c}\text { TABLE-1 } \\
\text { COLOUR FASTNESS TO WASHING }\end{array}$} \\
\hline \multirow{3}{*}{$\begin{array}{l}\text { Bleaching } \\
\text { technique }\end{array}$} & \multirow{3}{*}{$\begin{array}{l}\text { Bleaching } \\
\text { agent }\end{array}$} & \multicolumn{9}{|c|}{ Washing fastness } \\
\hline & & \multicolumn{3}{|c|}{$30 \mathrm{~min}$} & \multicolumn{3}{|c|}{$45 \mathrm{~min}$} & \multicolumn{3}{|c|}{$60 \mathrm{~min}$} \\
\hline & & $30^{\circ} \mathrm{C}$ & $60^{\circ} \mathrm{C}$ & $90^{\circ} \mathrm{C}$ & $30^{\circ} \mathrm{C}$ & $60^{\circ} \mathrm{C}$ & $90^{\circ} \mathrm{C}$ & $30^{\circ} \mathrm{C}$ & $60^{\circ} \mathrm{C}$ & $90^{\circ} \mathrm{C}$ \\
\hline \multirow{3}{*}{ Conventional } & $\mathrm{H}_{2} \mathrm{O}_{2}$ & $3-4$ & $3-4$ & $3-4$ & $3-4$ & $3-4$ & 4 & 4 & 4 & 4 \\
\hline & $\mathrm{NaOCl}$ & $3-4$ & $3-4$ & $3-4$ & $3-4$ & $3-4$ & 4 & $3-4$ & 4 & 4 \\
\hline & $\mathrm{NaBO}_{3}$ & $3-4$ & $3-4$ & $3-4$ & $3-4$ & $3-4$ & $3-4$ & $3-4$ & $3-4$ & 4 \\
\hline \multirow{3}{*}{ Ultrasonic } & $\mathrm{H}_{2} \mathrm{O}_{2}$ & 4 & 4 & 4 & $4-5$ & $4-5$ & $4-5$ & $4-5$ & $4-5$ & $4-5$ \\
\hline & $\mathrm{NaOCl}$ & $3-4$ & $3-4$ & $3-4$ & 4 & 4 & 4 & 4 & 4 & 4 \\
\hline & $\mathrm{NaBO}_{3}$ & $3-4$ & $3-4$ & $3-4$ & 4 & 4 & 4 & 4 & 4 & 4 \\
\hline
\end{tabular}

TABLE-2

COLOUR FASTNESS TO RUBBING

\begin{tabular}{|c|c|c|c|c|c|c|c|c|c|c|c|c|c|c|c|c|c|c|c|}
\hline \multirow{4}{*}{$\begin{array}{l}\text { Bleaching } \\
\text { technique }\end{array}$} & \multirow{4}{*}{$\begin{array}{c}\text { Bleaching } \\
\text { Agent }\end{array}$} & \multicolumn{18}{|c|}{ Rubbing fastness } \\
\hline & & \multicolumn{6}{|c|}{$30 \mathrm{~min}$} & \multicolumn{6}{|c|}{$45 \mathrm{~min}$} & \multicolumn{6}{|c|}{$60 \mathrm{~min}$} \\
\hline & & \multicolumn{2}{|c|}{$30^{\circ} \mathrm{C}$} & \multicolumn{2}{|c|}{$60^{\circ} \mathrm{C}$} & \multicolumn{2}{|c|}{$90^{\circ} \mathrm{C}$} & \multicolumn{2}{|c|}{$30^{\circ} \mathrm{C}$} & \multicolumn{2}{|c|}{$60^{\circ} \mathrm{C}$} & \multicolumn{2}{|c|}{$90^{\circ} \mathrm{C}$} & \multicolumn{2}{|c|}{$30^{\circ} \mathrm{C}$} & \multicolumn{2}{|c|}{$60^{\circ} \mathrm{C}$} & \multicolumn{2}{|c|}{$90^{\circ} \mathrm{C}$} \\
\hline & & Dry & Wet & Dry & Wet & Dry & Wet & Dry & Wet & Dry & Wet & Dry & Wet & Dry & Wet & Dry & Wet & Dry & Wet \\
\hline \multirow{3}{*}{ Conventional } & $\mathrm{H}_{2} \mathrm{O}_{2}$ & $3-4$ & $3-4$ & $3-4$ & $3-4$ & $3-4$ & $3-4$ & $3-4$ & $3-4$ & $3-4$ & $3-4$ & 4 & $3-4$ & 4 & $3-4$ & 4 & $3-4$ & 4 & $3-4$ \\
\hline & $\mathrm{NaOCl}$ & $3-4$ & $3-4$ & $3-4$ & $3-4$ & $3-4$ & $3-4$ & $3-4$ & $3-4$ & 4 & $3-4$ & 4 & $3-4$ & $3-4$ & $3-4$ & 4 & $3-4$ & 4 & $3-4$ \\
\hline & $\mathrm{NaBO}_{3}$ & $3-4$ & $3-4$ & $3-4$ & $3-4$ & $3-4$ & $3-4$ & $3-4$ & $3-4$ & $3-4$ & $3-4$ & $3-4$ & $3-4$ & $3-4$ & $3-4$ & $3-4$ & $3-4$ & $3-4$ & $3-4$ \\
\hline \multirow{3}{*}{ Ultrasonic } & $\mathrm{H}_{2} \mathrm{O}_{2}$ & 4 & 4 & 4 & 4 & 4 & 4 & $4-5$ & 4 & $4-5$ & 4 & $4-5$ & 4 & $4-5$ & 4 & $4-5$ & 4 & $4-5$ & 4 \\
\hline & $\mathrm{NaOCl}$ & $3-4$ & $3-4$ & $3-4$ & $3-4$ & 4 & $3-4$ & 4 & $3-4$ & 4 & $3-4$ & $4-5$ & $3-4$ & 4 & 4 & $4-5$ & 4 & $4-5$ & 4 \\
\hline & $\mathrm{NaBO}_{3}$ & $3-4$ & $3-4$ & $3-4$ & $3-4$ & $3-4$ & $3-4$ & 4 & $3-4$ & 4 & $3-4$ & 4 & $3-4$ & 4 & $3-4$ & 4 & 4 & 4 & 4 \\
\hline
\end{tabular}


The results for bleaching agents indicate that the grey scale rating of rubbing fastness for conventional technique was mostly good to very good (3-4) for all the bleaching agents hydrogen peroxide, sodium hypochlorite and sodium perborate. The ultrasonic assisted technique showed very good (4) and very good to excellent (4-5) rating for hydrogen peroxide; very good rating for sodium hypochlorite and good to very good (3-4) for sodium perborate.

In case of bleaching durations 30 and 45 min the rubbing fastness was mostly good to very good (3-4) and very good (4) for $1 \mathrm{~h}$ for conventional technique. The ultrasonic assisted technique mostly showed very good (4) rating for all bleaching durations.

For the effect of temperatures the rubbing fastness was mostly good to very good (3-4) for conventional technique but ultrasonic assisted technique showed better rating even at low temperatures.

On the basis of overall results, it is clear that ultrasonic assisted technique is better technique because it gives better rubbing fastness results.

Colour fastness to ironing: The results obtained by grey scale of colour fastness to ironing (dry and wet) of reactive dyed cotton fabric after bleaching with conventional and ultrasonic techniques under different bleaching agents, temperature and durations are presented in Table-3. The overall results show very good to excellent rating (4-5) for dry ironing and good to very good (3-4) wet ironing fastness. The results obtained were found to be better for some of the ultrasonically bleached samples as compared to the conventionally bleached samples. The ratings for the dry ironing fastness (4-5) were found to be in the same range for conventional as well as ultrasonic assisted techniques. The wet ironing fastness however, was found to be better (4) for some of the ultrasonically bleached samples as compared to the conventionally bleached samples.
The results for bleaching agents show that the grey scale rating of dry ironing fastness for conventional technique as well as ultrasonic assisted bleaching technique was mostly very good to excellent (4-5) for all the bleaching agents hydrogen peroxide, sodium hypochlorite and sodium perborate while in case of conventional technique the grey scale rating for wet ironing was mostly good to very good (3-4) for all the bleaching agents. For wet ironing fastness the ultrasonic assisted technique gave mostly very good (4) rating for hydrogen peroxide and good to very good (3-4) grey scale rating for sodium hypochlorite and sodium perborate. In case of all bleaching durations 30, 45 and 60 min the dry ironing fastness was mostly good to excellent (4-5) for conventional as well as ultrasonic assisted technique while the wet ironing fastness was mostly good to very good (3-4) for conventional as well as ultrasonic assisted technique.

For all the temperatures 30,60 and $90{ }^{\circ} \mathrm{C}$ the dry ironing fastness was also mostly good to excellent (4-5) for conventional as well as ultrasonic assisted technique while the wet rubbing fastness was mostly good to very good (3-4) for conventional as well as ultrasonic assisted technique.

Colour fastness to light: The results obtained for light fastness of reactive dyed cotton fabrics after bleaching with conventional and ultrasonic techniques under different bleaching agents, temperatures and durations are presented in Table-4. These results show that almost all samples showed better to good light fastness (5-6) rating for conventional as well as ultrasonic assisted technique.

No significant effect of bleaching technique is observed on light fastness of reactive dyed cotton fabrics. It could be due to the fact that light fastness is mainly dependant on dye used rather than other processing parameters.

\section{Conclusion}

The study showed that pre-treatment have a significant effect on fastness properties of fabrics. The fabric samples

TABLE-3

COLOUR FASTNESS TO IRONING

\begin{tabular}{|c|c|c|c|c|c|c|c|c|c|c|c|c|c|c|c|c|c|c|c|}
\hline \multirow{4}{*}{$\begin{array}{l}\text { Bleaching } \\
\text { technique }\end{array}$} & \multirow{4}{*}{$\begin{array}{c}\text { Bleaching } \\
\text { Agent }\end{array}$} & \multicolumn{18}{|c|}{ Ironing fastness } \\
\hline & & \multicolumn{6}{|c|}{$30 \mathrm{~min}$} & \multicolumn{6}{|c|}{$45 \mathrm{~min}$} & \multicolumn{6}{|c|}{$60 \mathrm{~min}$} \\
\hline & & \multicolumn{2}{|c|}{$30^{\circ} \mathrm{C}$} & \multicolumn{2}{|c|}{$60^{\circ} \mathrm{C}$} & \multicolumn{2}{|c|}{$90^{\circ} \mathrm{C}$} & \multicolumn{2}{|c|}{$30^{\circ} \mathrm{C}$} & \multicolumn{2}{|c|}{$60^{\circ} \mathrm{C}$} & \multicolumn{2}{|c|}{$90^{\circ} \mathrm{C}$} & \multicolumn{2}{|c|}{$30^{\circ} \mathrm{C}$} & \multicolumn{2}{|c|}{$60^{\circ} \mathrm{C}$} & \multicolumn{2}{|c|}{$90^{\circ} \mathrm{C}$} \\
\hline & & Dry & Wet & Dry & Wet & Dry & Wet & Dry & Wet & Dry & Wet & Dry & Wet & Dry & Wet & Dry & Wet & Dry & Wet \\
\hline \multirow{3}{*}{ Conventional } & $\mathrm{H}_{2} \mathrm{O}_{2}$ & $4-5$ & $3-4$ & $4-5$ & $3-4$ & $4-5$ & $3-4$ & $4-5$ & $3-4$ & $4-5$ & $3-4$ & $4-5$ & $3-4$ & $4-5$ & $3-4$ & $4-5$ & $3-4$ & $4-5$ & $3-4$ \\
\hline & $\mathrm{NaOCl}$ & $4-5$ & $3-4$ & $4-5$ & $3-4$ & $4-5$ & $3-4$ & $4-5$ & $3-4$ & $4-5$ & $3-4$ & $4-5$ & $3-4$ & $4-5$ & $3-4$ & $4-5$ & $3-4$ & $4-5$ & 4 \\
\hline & $\mathrm{NaBO}_{3}$ & 4 & $3-4$ & $4-5$ & $3-4$ & $4-5$ & $3-4$ & $4-5$ & $3-4$ & $4-5$ & $3-4$ & $4-5$ & $3-4$ & $4-5$ & $3-4$ & $4-5$ & $3-4$ & $4-5$ & $3-4$ \\
\hline \multirow{3}{*}{ Ultrasonic } & $\mathrm{H}_{2} \mathrm{O}_{2}$ & $4-5$ & 4 & $4-5$ & 4 & $4-5$ & 4 & $4-5$ & 4 & $4-5$ & 4 & 4 & 4 & $4-5$ & 4 & $4-5$ & 4 & 5 & 4 \\
\hline & $\mathrm{NaOCl}$ & $4-5$ & $3-4$ & $4-5$ & $3-4$ & $4-5$ & $3-4$ & $4-5$ & $3-4$ & $4-5$ & $3-4$ & $4-5$ & $3-4$ & $4-5$ & $3-4$ & $4-5$ & $3-4$ & $4-5$ & 4 \\
\hline & $\mathrm{NaBO}_{3}$ & $4-5$ & $3-4$ & $4-5$ & $3-4$ & $4-5$ & $3-4$ & $4-5$ & $3-4$ & $4-5$ & $3-4$ & $4-5$ & $3-4$ & $4-5$ & $3-4$ & $4-5$ & $3-4$ & $4-5$ & 4 \\
\hline
\end{tabular}

TABLE-4

COLOUR FASTNESS TO LIGHT

\begin{tabular}{|c|c|c|c|c|c|c|c|c|c|c|}
\hline \multirow{3}{*}{$\begin{array}{l}\text { Bleaching } \\
\text { technique }\end{array}$} & \multirow{3}{*}{$\begin{array}{l}\text { Bleaching } \\
\text { agent }\end{array}$} & \multicolumn{9}{|c|}{ Light fastness } \\
\hline & & \multicolumn{3}{|c|}{$30 \mathrm{~min}$} & \multicolumn{3}{|c|}{$45 \mathrm{~min}$} & \multicolumn{3}{|c|}{$60 \mathrm{~min}$} \\
\hline & & $30^{\circ} \mathrm{C}$ & $60^{\circ} \mathrm{C}$ & $90^{\circ} \mathrm{C}$ & $30^{\circ} \mathrm{C}$ & $60^{\circ} \mathrm{C}$ & $90^{\circ} \mathrm{C}$ & $30^{\circ} \mathrm{C}$ & $60^{\circ} \mathrm{C}$ & $90^{\circ} \mathrm{C}$ \\
\hline \multirow{3}{*}{ Conventional } & $\mathrm{H}_{2} \mathrm{O}_{2}$ & $5-6$ & $5-6$ & $5-6$ & $5-6$ & $5-6$ & $5-6$ & $5-6$ & $5-6$ & 6 \\
\hline & $\mathrm{NaOCl}$ & $5-6$ & $5-6$ & $5-6$ & $5-6$ & $5-6$ & 6 & $5-6$ & $5-6$ & $5-6$ \\
\hline & $\mathrm{NaBO}_{3}$ & $5-6$ & $5-6$ & $5-6$ & $5-6$ & $5-6$ & $5-6$ & $5-6$ & $5-6$ & $5-6$ \\
\hline \multirow{2}{*}{ Ultrasonic } & $\mathrm{H}_{2} \mathrm{O}_{2}$ & $5-6$ & $5-6$ & $5-6$ & $5-6$ & $5-6$ & 6 & $5-6$ & $5-6$ & 6 \\
\hline & $\mathrm{NaBO}_{3}$ & $5-6$ & $5-6$ & $5-6$ & $5-6$ & $5-6$ & $5-6$ & $5-6$ & $5-6$ & $5-6$ \\
\hline
\end{tabular}


dyed after ultrasonic bleaching clearly showed better fastness properties even at low temperature and less time as compared to conventional technique. This could be due to significant removal of impurities and better preparation of fabric for dyeing. Due to better preparation of cotton fabric, dye exhaustion and fixation might be increased which results in improved fastness properties. Further all processing variables have significant effect on colour fastness properties after conventional and ultrasonic assisted bleaching. Best results were obtained when fabric samples were dyed after ultrasonic assisted bleaching with hydrogen peroxide than other bleaching agents. Thus ultrasonic energy can be successfully used for improving the quality of the dyed fabrics.

\section{REFERENCES}

1. S.R. Karmakar, Chemical Technology in the Pre-treatment Processes of Textiles, Textile Science and Technology, Elsevier Science B.V. Sara Burgerhartstraat, 25 P.O. Box 211, 1000 AE Amsterdam, The Netherlands, Vol. 12 (1999).

2. C. Tomasino, Chemistry and Technology of Fabric Preparation and Finishing, College of Textile, NCSU, NC, USA, p. 60 (1993).

3. K.S. Suslic, Sci. Am., 2, 80 (1989).

4. V.S. Moholkar, V.A. Nierstrasz and M.M.C.G. Warmoeskerken, Autex Res. J., 3, 129 (2003).
5. M. Vouters, P. Rumeau, P. Tierce and S. Costes, Ultrasonics Sonochem., 11, 33 (2004).

6. C. Hurren, P. Cookson and X. Wang, Ultrasonics Sonochem., 15, 1069 (2008).

7. V.G. Yachmenev, E.J. Blanchard and A.H. Lambert, Ultrasonics, 42, 87 (2004).

8. C. Basto, T. Tzanov and A. Cavaco-Paulo, Ultrasonics Sonochem., 14, 350 (2007).

9. N.S.E. Ahmed, R.M. El-Shishtawy and M.M. Kamel, Pigm. Resin Technol., 36, 363 (2007).

10. K.A. Thakore, C.B. Smith and T.G. Clapp, Am. Dyestuff Reporter, 10, 30 (1990).

11. ISO, Textiles-Tests for colour fastness-Part C03: Colour Fastness to Washing, International Organization for Standardization (ISO) 1, ch. de la Voie-Creuse, Case postale 56 CH-1211 Geneva 20, Switzerland (1989).

12. ISO, Textiles-Tests for colour fastness-Part X12: Colour fastness to rubbing, International Organization for Standardization (ISO) 1, ch. de la Voie-Creuse, Case postale 56 CH-1211 Geneva 20, Switzerland (2001).

13. ISO, Textiles-Tests for colour fastness-Part X11: Colour fastness to hot pressing, International Organization for Standardization (ISO) 1, ch. de la Voie-Creuse, Case postale 56 CH-1211 Geneva 20, Switzerland (1994).

14. ISO, Textiles-Tests for colour fastness-Part B02: Colour fastness to light, International Organization for Standardization (ISO) 1, ch. de la Voie-Creuse, Case postale 56 CH-1211 Geneva 20, Switzerland (1999).

15. M.R. Hoffmann, I. Hua and R. Hochemer, Ultrasonics Sonochem., 3, 163 (1996) 